\title{
EXFOLIATION JOINTS AND ICE ACTION
}

\author{
By W. B. Harland \\ (Department of Geology, Cambridge)
}

\begin{abstract}
Some generally accepted views on joints in rocks, particularly exfoliation joints, are summarized. ABSTRACT. Some generally accepted views on joints in rocks, particularly exfoliation joints, are summarized.
Lewis' pressure release hypothesis is assessed in relation thereto. An additional hypothesis is suggested whereby the existing stress system in rocks due to the removal of overburden which would favour exfoliation, would be augmented by freezing of the saturated rock when the ice retreats, so triggering this type of extension joint.

Zusammenfassung. Die Arbeit enthält eine Zusammenfassung allgemein anerkannter Meinungen über Sprünge in Felsen, insbesondere Abschalungssprünge. Die Druckentlastungs-Hypothese von Lewis wird in diesem Zusammenhang geprüft. Als zusätzliche Hypothese wird vorgeschlagen, dass die im Felsen vorhandenen SpanZusammenhang geprüft. Als zusätzliche Hypothese wird vorgeschlagen, dass die im Felsen des gesättigten Felsen nach Gletscherrückzug, und so Abschalungen auslösen.
\end{abstract}

This paper expands my contribution to a discussion of Mr. W. V. Lewis' paper "Pressure release and glacial erosion" 1 . My approach will be to outline a widely held view of joints, and exfoliation joints in particular; to consider Mr. Lewis' contribution in relation to these and to offer an additional possible explanation of some of the observations recorded. By exfoliation joints I refer to those joints which are roughly parallel to the topography and appear to be due to denudation; such joints in granites have been termed "sheeting".

\section{JoINTs}

Joints in rocks are clean cut fractures with negligible shear displacement and varying degree of openness; they penetrate all rocks to some extent and often fall into more or less well defined sets which may differ in degree of persistence, spacing, curvature and parallelism. Residual joints not belonging to an obvious set may or may not, on quantitative analysis, reveal a preferred orientation.

From a number of characteristics, including their relationship to other tectonic structures, joints are often divided into two main types, namely shear ("compression") joints and extension ("tension") joints. Shear fractures form an angle with the direction of maximum compression, while extension fractures are parallel thereto and normal to the direction of maximum compression. In other words shear joints contain the direction of the intermediate principal stress, and extension joints contain the maximum and intermediate directions, thus effecting an extension normal to their surface and in the direction of minimum stress. Both types of fracture have been produced experimentally and the above theory often enables joints to be correlated with other structures due to the same stress orientation and thus to be fitted into the tectonic sequence ${ }^{2}$. Shear joints may develop as conjugate sets, or as a single set in conjugation with a fault or other fracture system, as demonstrated by a recent example ${ }^{3}$.

There are two senses in which most, if not all, joints may be regarded as due to "pressure release". First it seems that many joint systems develop at a late stage in deformation at a time of decreasing stress. This is certainly the case in many extension joints (e.g. AC-joints).

Secondly, there is no doubt that the removal of over-burden by denudation so modifies the stresses in the rocks that predetermined joints are made more evident (e.g. by opening). It is not known in what state joints, already determined tectonically, may exist at depth. Lewis, however, assumes that certain massive rocks at depth are not effectively jointed. If this were so it would make deep erosion by thick ice more difficult. However, the difficulty may, he argues, be overcome by "pressure release", due to variation in ice load, which joints the rock.

Evidence quoted, to show that rocks at depth are subject to stresses and undergo readjustment on release of confining pressure, adds little to our knowledge. The practical importance of this in 
granite quarrying ${ }^{4}$, in mining 5 or in drilling when a core expands noticeably on removal from the bore-hole, has long been known and applied. The experiments carried out more recently by Mr. D. Masson Smith 6 show a complex anisotropic pattern of readjustment of newly quarried rock over a period of a few months, very difficult to interpret without a further prolonged series of experiments. The experiments so far as they go confirm, but do not, unfortunately, clarify the pattern of readjustment.

\section{ExFoliation JoINTS}

Lewis applies this experience to the interpretation of exfoliation joints. Most literature on joints is concerned with their tectonic significance, and only makes mention of exfoliation jointing in order to exclude it from consideration. However, such jointing, under various names, is generally recognized. A standard text book in structural geology 7 distinguishes "sheeting" from "jointing" by the following characteristics:-The (sheeting) fractures are (a) curved and essentially parallel to the topographical surface, except in regions of recent rapid erosion; (b) best exposed in artificial openings such as quarries; (c) close together at the surface of the earth, the spacing increasing with depth and dying out altogether a few tens of feet deep; at greater depths parallel planes of weakness have been used by quarrymen; (d) sheeting is best known in granitoid rocks, but also in massive sandstone.

The hypothesis generally favoured for the formation of sheeting is that rock at depth is under general compression, and expands on the removal of overload. While this expansion may take place freely in a direction normal to the topographical surface, the rock is constrained in directions parallel to the surface. This results in relative compression parallel to the topographical surface, with consequent extension fracturing. Extension fracture, unlike shear fracture, allows the rock to expand in the direction of minimum principal stress by fractures normal to it. Such is known not only from other types of jointing, but also from experimental investigations as quoted by Lewis 9 .

Any jointing is of importance in denudation, and rocks which lack a close system of tectonic joints (i.e. massive rocks such as some granites) will more readily acquire an exfoliation system; for the stresses producing new joints in rock would, in the first place, open up any existing suitably orientated tectonic joints, and such are generally found.

The identification of exfoliation jointing is more difficult, however, than its explanation; for fracture surfaces parallel to topography may alternatively be due to an original tectonic system which subsequently has controlled topography.

Generally there are many joints whose origin is obviously either tectonic or denudational. Closer study, possibly statistical, may reduce the number of unexplained or ambiguous fractures, but a residue is likely to remain. In any case identification of exfoliation joints will often depend on their exclusion from tectonic explanation. Such exclusion is not always satisfactory since there are innumerable joints clearly not of denudational origin whose tectonic origin has yet to be accounted for.

Exfoliation joints are thus more easily identified, as well as explained, in the more massive rocks and there are good reasons why granites and granite gneisses ${ }^{10}$ as well as glaciers are found in mountainous regions.

\section{Glacial Unloading Mechanism}

The possibility of stresses induced by a reduction in ice load was mentioned briefly by Wheeler in $194^{11}$. Lewis, however, argues the erosional significance of such a possibility, for, beneath a glacier, rock loosened by jointing may be removed at depths possibly not reached by thaw-freeze processes. Such could take place in the opening up of pre-existing systems; but Lewis suggests that in relatively unjointed rocks beneath a glacier exfoliation jointing, induced by variation of the ice load, would be an important factor.

It is probable that stresses induced by variations in the thickness of ice, if effective in this way, 
would act by combining with pre-existing stresses. Rock fracture at the surface generally, is probably due to a combination of residual hypogene stresses and of those due to reversible epigene processes. Thus attempts to split rock samples by experimental thaw-freeze or heat-chill often fail to simulate cold or hot desert conditions. Similar processes applied to rocks under stress may serve as a sufficient trigger.

\section{Thaw-Freeze Mechanism}

An alternative and possibly more powerful trigger effect, which could account for the observations of exfoliation and arching exposed beneath retreating ice ${ }^{12}$, is now suggested. Even in cold regions with deep permafrost the ground may not be frozen beneath large glaciers. This is borne out by mining operations. Therefore glacial retreat may allow the freezing of newly exposed ground which is likely to be saturated with water. The resulting compression would so increase the principal stresses parallel to the surface, in relation to the normal stress, as to accentuate exfoliation conditions. Once formed, a crack would fill with ice and increase the arching effect as Lewis suggests. This mechanism does not conflict with that of glacial unloading proposed by Lewis, indeed the two may reinforce each other.

It would seem to be more powerful, being due to fluctuations of the ice front in a cold climate, and almost independent of thickness of ice cover. However, the thickness of the ice may be related to the position of the front in a general way and a quantitative comparison could be attempted. Even so it is difficult to evaluate the effectiveness of these two, or of other trigger mechanisms, depending as they must on the rate of change of stress, the number of reversals in the process, and the residual tectonic stress pattern.

With a thaw-freeze mechanism in mind I remarked to Mr. Lewis in 1947 on the granite jointing recently seen in certain alpine valleys and questioned whether there was not some special connexion between exfoliation and glaciation. I regretted not having had this in mind earlier, for in 1945 I could have made a better case than I did 13,14 for a low level glaciation in the Red Basin, Szechwan. I then interpreted quite striking exfoliation joints in massive sandstones as due to thermal expansion in hot interglacial deserts rather than to periglacial freezing. Other geomorphological aspects suggested corrie erosion.

MS. received 28 November 1955

\section{RE F E R E N C E S}

1. Lewis, W. V. Pressure release and glacial erosion. Fournal of Glaciology, Vol. 2, No. 16, 1954, p. 417-22.

1. Lewis, W. V. Pressure release and glacial erosion. Fournal of Glaciology, Vol. 2, No. 16, 1954, p. 417-22.
2. Harland, W. B. Tectonic facies, orientation, sequence, style and date. Geological Magazine. Vol. 93, No. 2, 1956, p. 1 II -20 .

3. Dawson-Grove, G. E. Analysis of minor structures near Ardmore, County Waterford, Eire. Quarterly fournal of the Geological Society of London, Vol. II I, No. 44I, 1955, p. I-2 I.

4. Dale, T. N. The granites of Vermont. U.S. Geological Survey. Bulletin No. 404, 1909, p. $17-18$.

5. Bucky, P. B. (Presiding). Rock bursts. A symposium. American Institute of Mining and Metallurgical Engineers. Technical Publication No. 1468,1942, p. $\mathrm{I}^{-} 56$. [With references to earlier literature.]

6. Lewis, W. V. op. cit., p. 421 .

7. Billings, M. P. Structural geology. New York, 1942, p. 128-29.

8. $o p$. cit., p. 129.

9. Bridgman, P. W. Reflections on rupture. Fournal of Applied Physics, Vol. 9, 1938, p. 517-28.

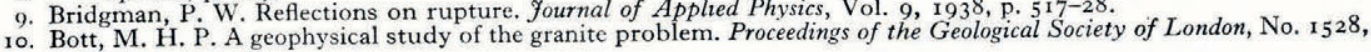
I 955 , p. II $19-20$.

II. Bucky, P. B. op. cit., p. 26.

12. Lewis, W. V. op cit., p. $421-22$.

13. Harland, W. B. The physiographical history of Western Szechuan. Fournal of the West China Border Research Society (Chengtu), Vol. 15, Series B, 1945, p. 1-19.

14. Whittington, H. B. The physiographical history of Western Szechuan-a review and discussion. Geological Magazine, Vol. 83 , No. 3, 1946, p. 141-46. 